Available online at http://journal.stkip-andi-matappa.ac.id/index.php/histogram/index

Histogram : Jurnal Pendidikan Matematika ., 2019, 172 - 181

\title{
PERBANDINGAN MODEL PEMBELAJARAN TGT BERBANTUAN KARTU MATEMATIKA ASYIK DAN MODEL PEMBELAJARAN LANGSUNG
}

\author{
Indah Rahayu Panglipur ${ }^{1 *}$, Ria Amalia ${ }^{2}$ \\ 1,2 IKIP PGRI Jember \\ * Corresponding Author. Email: indahmath89@ikipjember.ac.id \\ Received: 06 Agustus 2019; Revised: 18 Agustus 2019 ; Accepted: 30 September 2019
}

\begin{abstract}
ABSTRAK
Penelitian ini membandingkan antara model pembelajaran kooperatif tipe TGT (Team Games Tournament) yang dibantu oleh Kartu Matematika Asyik dan Model Pembelajaran Langsung dalam hal hasil pembelajaran mereka. Desain penelitian eksperimen semu dipilih dalam penelitian ini. Populasi adalah siswa kelas X SMK Negeri 3 Jember pada tahun akademik 20018-2019. Sedangkan sampel dalam penelitian ini diambil secara acak kelompok atau cluster random sampling. Dalam penelitian ini, data diperoleh dengan cara tes untuk mengetahui hasil belajar kemudian data pengujian hipotesis dianalisis dengan bantuan program SPSS. Hasil penelitian menunjukkan bahwa terdapat perbedaan hasil belajar siswa yang mendapatkan model pembelajaran kooperatif tipe TGT (Team Games Tournament) yang dibantu oleh Kartu Matematika Asyik dan Model Pembelajaran Langsung. Hasil belajar siswa yang mendapatkan model pembelajaran kooperatif tipe TGT (Team Games Tournament) yang dibantu oleh Fun Mathematics Card lebih baik dari pada siswa yang mendapatkan Model Pembelajaran Langsung.

Kata Kunci: TGT, Kartu Matematika Asyik. Langsung

How to Cite: Panglipur, I, R., Amalia, R. (2019). Perbandingan Model Pembelajaran TGT Berbantuan Kartu Matematika Asyik dan Model Pembelajaran Langsung. Histogram: Jurnal Pendidikan Matematika, 3(2), 172 - 181, doi: http://dx.doi.org/10.31100/histogram.v3i2.428 Permalink/DOI: http://dx.doi.org/10.31100/histogram.v3i2.428
\end{abstract}

\section{PENDAHULUAN}

Berbagai macam model pembelajaran yang ada tentunya memberikan variasi pilihan kepada pendidik dalam melaksanakan pembelajaran. Akan tetapi seringkali dijumpai bahwa pendidik cenderung melakukan pembelajaran secara monoton tanpa variasi model pembelajaran. Adanya keberagaman masalah, karakter peserta didik dalam pembelajaran tidak mampu mengubah model pembelajaran yang dilakukan. Alasan klasik yang dikemukakan yaitu pendidik telah asyik dan merasa nyaman dengan pembelajaran yang dilakukan selama ini. Padahal kompetensi pedagogik merupakan komponen utama yang berpengaruh terhadap keberhasilan pembelajaran. Sependapat dengan hal tersebut, (Coe, Aloisi, Higgins, \& Major, 2014) menyatakan pendidik yang paling efektif dan mampu menyajikan proses pembelajaran yang hebat. Pendidik tersebut menguasai bahan 


\section{Histogram: Jurnal Pendidikan Matematika, 3 (2), 2019 - 173 Indah Rahayu Panglipur, Ria Amalia}

ajar, mampu mengembangkan dan menyajikan proses pembelajaran sesuai konsep yang lebih sederhana dan mudah dipahami oleh peserta didik, mampu memahami cara berfikir peserta didik terhadap bahan ajar yang mereka sajikan, melakukan evaluasi secara baik dan kontinu, bahkan mampu mengidentifikasi dan mengatasi terhadap miskonsepsi yang terjadi siswa.

Berdasarkan wawancara dengan guru matematika, bapak Firzon, S.Pd diperoleh informasi bahwa Selama ini beliau menerapkan model pembelajaran langsung (Direct Instruction) dalam pembelajaran matematika yang dilakukan. Pembelajaran tersebut banyak memberi pengalaman belajar serta kesempatan kepada siswa untuk latihan baik secara mandiri maupun secara terbimbing. Selain itu, Model pembelajaran langsung cukup efektif digunakan dalam menyampaikan materi secara terstruktur. Model pembelajaran langsung banyak memberikan kesempatan kepada guru untuk ceramah dan dapat menciptakan lingkungan belajar yang kondusif. Memang guru terlihat lebih aktif saat proses pembelajaran dibandingkan dengan siswa. Sehingga, penyampaian informasi berkaitan dengan materi disampaikan secara jelas di awal pembelajaran. Hal tersebut membuat siswa belum memiliki kemampuan mengeksplore pengetahuan secara mandiri.

Diantara berbagai model pembelajaran kooperatif, yang memberikan banyak keseempatan kepada siswa untuk belajar dan berlatih serta meningkatkan kemampuan menyelesaikan masalah yaitu Model Pembelajaran kooperatif tipe TGT (Team GamesTournament). Dalam pembelajaran ini, siswa dituntut untuk selalu aktif dalam menyelesaikan permasalahan matematika dalam bentuk turnamen. Siswa diharapkan mengerahkan kemampuan terbaiknya dalam setiap pembelajaran. Dengan adanya tournamen, maka kepercayaan diri, kemandirian serta sportifitas siswa dilatih. Tentunya Model Pembelajaran kooperatif tipe TGT (TeamGames Tournament) membutuhkan media pembelajaran. Dalam hal ini, dipilihlah media Kartu Matematika Asyik untuk membantu pelaksanaan tournament.

Baik Model Pembelajaran kooperatif tipe TGT (Team Games Tournament) berbantuan media Kartu Matematika Asyik maupun pembelajaran langsung (Direct Instruction) memiliki kesamaan fase dalam hal memberikan kesempatan dalam berlatih menyelesaikan permasalahan. Oleh karena itu, peneliti tertarik untuk membandingkan kedua model pembelajaran tersebut. Peneliti ingin mengetahui tentang apakah siswa SMKN 3 Jember yang melakukan proses pembelajaran model TGT (Team Games Tournament) berbantuan media Kartu Matematika Asyik memiliki hasil belajar lebih tinggi daripada siswa yang melakukan proses pembelajaran langsung (Direct Instruction)? 


\section{Histogram: Jurnal Pendidikan Matematika, 3 (2), 2019 - 174 Indah Rahayu Panglipur, Ria Amalia}

Pembelajaran kooperatif adalah model pembelajaran yang menekankan pada suatu kelompok kecil dimana setiap peserta didik dalam kelompoknya melakukan kerjasama dan memaksimalkan kegiatan pembelajaran guna menyelesaikan tugas yang berikan. (Coe et al., 2014) menyebutkan terdapat delapan manfaat pembelajaran kooperatif yaitu: (1)Adanya peningkatan pemahaman pengetahuan, (2) Pemberian penguatan keterampilan sosial, (3) Pemberian keleluasaan siswa dalam membuat keputusan, (4) terciptanya lingkungan belajar yang aktif, (5) Peningkatan kepercayaan diri siswa, (6) Menghargai perbedaan dalam hal gaya belajar, (7) tanggung jawab siswa lebih meningkat, dan (8) Fokus terhadap keberhasilan masing-masing siswa.

Pembelajaran Team Game Tournament (TGT) melibatkan siswa dalam kegiatan berdiskusi serta memuat unsur permainan serta reinforcement. Dalam pembelajaran Team Game Tournament terdapat turnamen akademik sehingga siswa berlomba-lomba dalam memperoleh poin. Hal inilah yang membuat siswa lebih termotivasi dalam pembelajaran. (Slavin, 2014) (Slavin, 2014)menjelaskan bahwa terdapat 5 tahap dalam pembelajaran kooperatif tipe TGT yaitu: a) Class-Presentation (Penyajian/Presentasi kelas), b) Team (Kelompok), c) Game (Permainan), d) Turnament, e) Penghargaan terhadap Kelompok.

Untuk menunjang model pembelajaranTeam Game Tournament (TGT) diperlukan suatu media. Media yang dipilih yaitu Media Kartu Matematika Asyik. Media tersebut terdiri dari Kartu Soal, Kartu jawab serta Lembar penilaian. Kartu Matematika Asyik yang dirancang terbuat dari kertas bufallow. Berikut ini gambar kartu yang digunakan dalam pembelajaran.

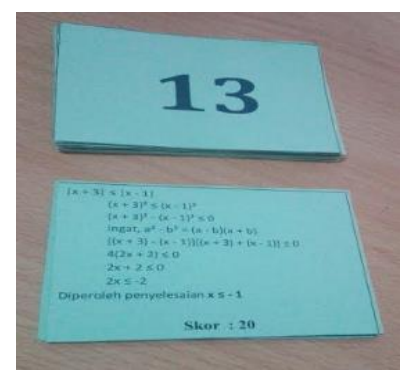

Gambar 1. Kartu Matematika Asyik

Pembelajaran langsung yaitu model yang membantu siswa dalam memperoleh keterampilan dan mendapatkan informasi secara bertahap. Penyampaian materi disajikan 


\section{Histogram: Jurnal Pendidikan Matematika, 3 (2), 2019 - 175 Indah Rahayu Panglipur, Ria Amalia}

secara deduktif sistematis. Sebagaimana pendapat (Setyosari, 2012) model pembelajaran langsung adalah model pembelajaran yang sengaja didesain guna mempermudah proses belajar siswa yang berhubungan tentang pengetahuan deklaratif serta pengetahuanprosedural secara terstruktur dan baik. Proses penyampaian materi/konsep diajarkan melalui pola kegiatan yangdilakukan secara bertahap selangkah demi selangkah.

Dalam buku (Trianto, 2010) yang berjudul Mendesain Model Pembelajaran Inovatif-Progresif, Kardi mengemukakan bahwa terdapat 5 fase dalam model pembelajaran langsung yaitu: 1) penyampaian tujuan serta persiapan siswa, 2) mendemontrasikan pengetahuan serta keterampilan, 3) Membimbingpelatihan tugas, 4) Pengecekan ulang pemahaman sekaligus pemberian umpan balik, 5) Pemberian pelatihan lanjutan . Kelima fase tersebut menjadi acuan serta pedoman dalam melaksanakan penelitian lebih lanjut.

\section{METODE PENELITIAN}

\section{A. Jenis Penelitian}

Jenis penelitian adalah eksperimen semu. Rancangan eksperimen semu digunakan untuk membandingkan hasil belajar siswa di kelas eksperimen serta kelas kontrol. Model pembelajaran kooperatif tipe TGT berbantuan Kartu Matematika Asyik diterapkan pada kelas eksperimen sedangkan pembelajaran langsung diterapkan pada kelas kontrol. Variabel bebas dalam penelitian ini yaitu pembelajaran kooperatif tipe TGT berbantuan Kartu Matematika Asyik dan variabel terikatnya adalah hasil belajar terhadap model pembelajaran.

\section{B. Prosedur Penelitian}

Peneliti mengadakan pengambilan data dengan melakukan 2 kali pertemuan. Pada pertemuan terakhir diberikan soal tes pada masing-masing kelas. Kelas kontrol diberikanperlakukandengan pembelajaran langsung dan kelas eksperimen menggunakan pembelajaran TGT dengan menggunakan media kartu asyik

\section{Setting Penelitian}

Siswa kelas X SMKN 3 Jember tahun pelajaran 2018-2019 sebagai Populasi terhadap penelitian. Oleh karena itu, diambil sampel penelitian yaitu dua kelas X jurusan perhotelan dengan kelas eksperimen terdiri dari 35 siswa dan sebanyak 35 siswa sebagai kelas kontrol. 


\section{Histogram: Jurnal Pendidikan Matematika, 3 (2), 2019 - 176 Indah Rahayu Panglipur, Ria Amalia}

Untuk memperoleh informasi berkaitan tentang apakah sampel memiliki kemampuan awal yang homogen atau tidak homogen maka akan dilakukan Uji hipotesis yaitu uji dua sample berpasangan dengan taraf kepercayaan 5\%. Adapun hipotesis nol (Ho) serta hipotesis alternatif $\left(\mathrm{H}_{1}\right)$ yang digunakan adalah:

$$
\begin{aligned}
& \text { Ho }: \mu_{1}=\mu_{2} \\
& H_{1}: \mu_{1} \neq \mu_{2} \\
& \text { Keterangan: } \\
& \mu_{1}: \text { rata - rata kelas eksperimen } \\
& \mu_{2}: \text { rata - rata kelas kontrol }
\end{aligned}
$$

Ho: Tidak ada perbedaan terhadap hasil belajarsiswa yang telah mendapatkan pembelajaran kooperatif tipe TGT berbantuan Kartu Matematika Asyik dengan siswa yang telah mendapatkan pembelajaran langsung

$\mathrm{H}_{1}$ : Ada perbedaan terhadap hasil belajar siswayang telah mendapatkan pembelajaran kooperatif tipeTGT berbantuan Kartu Matematika Asyik dengan siswa yang telah mendapatkan pembelajaran langsung

Untuk menjawab rumusan masalah di atas, akan dilakukan uji hipotesis untuk memperoleh informasi apakah hasil belajar siswa yang mendapatkan pembelajaran kooperatiftipe TGT berbantuan Kartu Matematika Asyik dibandingkan hasil belajar siswa yang mendapatkan pembelajaran langsung. Hipotesis nol (Ho) serta hipotesis alternatif $\left(\mathrm{H}_{1}\right)$ sebagai berikut:

$$
\begin{aligned}
& \text { Ho: } \mu_{1}=\mu_{2} \\
& \mathrm{H}_{1}: \mu_{1}>\mu_{2}
\end{aligned}
$$

\section{Keterangan:}

$\mu_{1}$ : rata - rata kelas eksperimen

$\mu_{2}$ : rata - rata kelas kontrol

Ho: Tidak ada perbedaan terhadap hasil belajar antara siswa yang telah mendapatkan pembelajaran kooperatif tipe TGT berbantuan Kartu Matematika Asyik dengan siswa yang mendapatkan pembelajaran langsung 


\section{Histogram: Jurnal Pendidikan Matematika, 3 (2), 2019 - 177 Indah Rahayu Panglipur, Ria Amalia}

$\mathrm{H}_{1}$ : Hasil belajar siswa yang telah mendapatkan pembelajaran kooperatif tipe TGT berbantuan Kartu Matematika Asyik lebih baik dibandingkan dengan siswa yang telah mendapatkan pembelajaran langsung

\section{HASIL DAN PEMBAHASAN}

\section{A. Hasil Penelitian}

Pengujian data tentang kemampuan awal dari sampel penelitian sangat diperlukan untuk memeriksa apakah sampel yang telah diambil memiliki kemampuan awal yang homogen. Data ini menunjukkan kemampuan yang dimiliki siswa sebelum diberikan perlakuan. Untuk itu dilakukan pre-test pada kelas kontrol serta kelas eksperimen. Soal pretest yang diberikan berupa soal essay sebanyak 10 soal.

Pengujian data kemampuan awal siswa didasarkan pada pengambilan hipotesis berikut.

Ho: Tidak ada perbedaan hasil belajar siswa yang mendapatkan pembelajaran kooperatif tipe TGT berbantuan Kartu Matematika Asyik dengan siswa yang mendapatkan pembelajaran langsung

$\mathrm{H}_{1}$ : Ada perbedaan hasil belajar siswa yang mendapatkan pembelajaran kooperatif tipe TGT berbantuan Kartu Matematika Asyik dengan siswa yang mendapatkan pembelajaran langsung

Ho ditolak apabila nilai Sig $<0,05$

Berikut ini disajikan data tentang kemampuan awal dari sample penelitian.

Tabel 1. Deskripsi data kemampuan awal siswa

\begin{tabular}{cccccc}
\hline Hasil & Kelompok & N & Rata-rata & $\begin{array}{c}\text { Standar } \\
\text { Deviasi }\end{array}$ & $\begin{array}{c}\text { Std. Error } \\
\text { Rata-rata }\end{array}$ \\
\cline { 2 - 6 } Belajar & Kelas Kontrol & 35 & 74,37 & 4,759 & 0,804 \\
\cline { 2 - 6 } & $\begin{array}{c}\text { Kelas } \\
\text { Eksperimen }\end{array}$ & 35 & 75,49 & 8,975 & 1,517
\end{tabular}

(Sumber: Data Primer, Tahun: 2019)

Berdasarkan tabel 1 tersebut, diperoleh informasi yaitu nilai rata - rata dari hasil belajar dari siswa di kelas kontrol sebesar 74,37 dan rata - rata dari hasil belajar dari siswa di kelas eksperimen sebesar 75,49. Dengan demikian hasil belajar siswa antara kelas ekperimen serta kelas kontrol memiliki kecenderungan yang sama. 
Tabel 2. Hasil pengujian data kemampuan awal siswa

\begin{tabular}{ccc}
\hline Yang dibandingkan & Nilai Asymp.Sig. (2-tailed) & Keterangan \\
\hline $\begin{array}{c}\text { Pre Test Kelas Kontrol } \\
\text { dan Pretest Kelas }\end{array}$ & 0,519 & Signifikan \\
Eksperimen & & \\
\hline
\end{tabular}

(Sumber: Data Primer, Tahun: 2019)

Berdasarkan tabel 2, diperoleh nilai Asymp.Sig. (2-tailed) $=0,519$. Karena nilai Asymp.Sig. (2-tailed) > 0,05, maka Ho diterima. Dengan kata lain, tidak ada perbedaan yang signifikan dari kemampuan awal diantara kedua kelas kontrol serta kelas eksperimen.

Kemampuan awal siswa pada kelas eksperimen serta pada kelas kontrol menunjukkan tidak ada perbedaan. Dengan kata lain, perbedaan kemampuan awal bukanlah menjadi faktor penghalang dalam melakukan eksperimen. Sehingga kegiatan penelitian dapat dilanjutkan dengan memberikan perlakuan pada kelas eksperimen. Kemudian, pengujian terhadap hasil belajar siswa di kelas eksperimen serta kelas kontrol setelah diberikan perlakuan berupa penerapan kedua model pembelajaran dapat dilaksanakan.

Pada penelitian ini, setiap kelas kontrol dan kelas eksperimen telah dilakukan pembelajaran dalam 4 kali pertemuan/tatap muka. Pelaksanaan postest dilakukan pada pertemuan keempat. Pelaksanaan pembelajaran pada kelas eksperimen dilakukan dengan baik dan lancar sesuai dengan RPP yang telah disusun. Pelaksanaan turnamen dilakukan dalam 2 tahap. Tahap pertama, dilakukan turnamen antar individu untuk mendapatkan pemain terbaik pada masing-masing kelompok. Sedangkan tahap kedua yaitu untuk mencari pemain terbaik di kelas. Hasil kegiatan turnamen dapat disajikan pada tabel di bawah:

Tabel 3. Rekapitulasi kegiatan turnamen 1

\begin{tabular}{cccccccc}
\hline Kelompok & Aljabar & Geometri & Kalkulus & Trigonometri & Pascal & Graf & Segitiga \\
\hline S1 & 90 & 110 & 80 & $\mathbf{1 3 5}$ & 105 & 75 & 85 \\
\hline S2 & 85 & 85 & 105 & 95 & 90 & 80 & 85 \\
\hline S3 & $\mathbf{1 0 5}$ & 95 & $\mathbf{1 2 5}$ & 105 & $\mathbf{1 2 5}$ & 105 & $\mathbf{1 0 5}$ \\
\hline S4 & 85 & 95 & 95 & 90 & 85 & $\mathbf{1 3 5}$ & 90 \\
\hline S5 & 75 & $\mathbf{1 1 5}$ & 75 & 85 & 110 & 95 & 85 \\
\hline Total & 440 & 500 & 480 & 510 & 515 & 490 & 450 \\
\hline
\end{tabular}

(Sumber: Data Primer, Tahun: 2019)

Keterangan:

S1 adalah subjek ke-1 di kelompok, S2 adalah subjek ke-2 di kelompok, dst.

Subjek yang memperoleh skor tertinggi di kelompok ditampilkan dengan cetak tebal. 


\section{Histogram: Jurnal Pendidikan Matematika, 3 (2), 2019 - 179 Indah Rahayu Panglipur, Ria Amalia}

Dari tabel 3, siswa yang melakukan turnamen ke tahap selanjutnya yaitu 7 siswa sebagai perwakilan masing-masing kelompok. Setelah dikasanakan turnamen tahap selanjutnya diperoleh skor sebagai berikut. Sedangkan kelompok terbaik yaitu kelompok yang memperoleh skor total tertinggi yaitu diraih oleh kelompok Pascal.

Tabel 4. Rekapitulasi kegiatan turnamen 2

\begin{tabular}{cccccccc}
\hline Kelompok & Aljabar & Geometri & Kalkulus & Trigonometri & Pascal & Graf & Segitiga \\
\hline Skor & 95 & 115 & 80 & 150 & 105 & 75 & 85 \\
\hline
\end{tabular}
(Sumber: Data Primer, Tahun: 2019)

Berdasarkan tabel 4 diperoleh informasi bahwa skor tertinngi dalam pelaksanaan turnamen yaitu 150 dan diraih perwakilan siswa dari kelompok trigonometri. Dengan demikian S1 dari kelompok trigonometri yang telah berhasil menjadi siswa terbaik dalam pelaksanaan turnamen. Sedangkan pada kelas control, pembelajaran langsung yang dilakukan dengan berbantuan LKS yang dibuat oleh guru. Pada tahap demonstrasi, guru mengalami kesulitan dalam mendemontrasikan konsep karena mengacu pada permasalahan yang diberikan. Guru cenderung hanya memberikan bimbingan secara procedural tentang cara menyelesaikan masalah. Hal ini didukung pendapat Zahriani (2014) bahwa Model Direct Instruction relevan digunakan dalam menjelaskan konsep dan procedural. Di setiap pertemuan siswa diberikan 10 soal sebagai latihan. Di pertemuan pertama hanya 6 soal yang dapat terselesaikan, di pertemuan kedua hanya 7 soal terselesaikan, dan 9 soal berhasil diselesaikan dengan baik di pertemuan ketiga. Pelaksanaan posttest dilaksanakan pada pertemuan keempat.

\section{B. Pembahasan}

Analisa data posttest pada kedua kelas digunakan sebagai dasar dalam pengambilan keputusan dalam membandingkan hasil belajar manakah yang lebih baik yang disajikan dalam gambar berikut.

Tabel 5. Deskripsi data hasil belajar siswa

\begin{tabular}{cccccc}
\hline & Kelompok & N & Rata-rata & $\begin{array}{c}\text { Standar } \\
\text { Deviasi }\end{array}$ & $\begin{array}{c}\text { Std. Error } \\
\text { Rata-rata }\end{array}$ \\
\cline { 2 - 6 } Hasil & Kelas Kontrol & 35 & 74,31 & 3,017 & 0,510 \\
\cline { 2 - 6 } & $\begin{array}{c}\text { Kelas } \\
\text { Eksperimen }\end{array}$ & 35 & 81,89 & 9,048 & 1,529 \\
\hline
\end{tabular}

(Sumber: Data Primer, Tahun: 2019) 


\section{Histogram: Jurnal Pendidikan Matematika, 3 (2), 2019 - 180 Indah Rahayu Panglipur, Ria Amalia}

Berdasarkan tabel 5 di atas, diperoleh skor rata-rata hasil belajar kelas control yaitu 74,31 dan rata-rata hasil belajar kelas eksperimen yaitu 81,89. Dengan demikian hasil belajar antara kelas ekperimen lebih baik dari pada rata-rata hasil belajar kelas kontrol.

Tabel 6. Hasil pengujian data hasil belajar siswa

\begin{tabular}{ccc}
\hline Yang dibandingkan & Nilai Asymp.Sig. (2-tailed) & Keterangan \\
\hline Postest Kelas Kontrol & 0,001 & Signifikan \\
dan Postest Kelas & & \\
Eksperimen & & \\
\hline
\end{tabular}

(Sumber: Data Primer, Tahun: 2019)

Berdasarkan tabel 6 di atas, diperoleh nilai Asymp.Sig. (2-tailed) =0,001. Karena skor Asymp.Sig. (2-tailed) < 0,05, sehingga dapat diambil keputusan $\mathrm{H}_{1}$ diterima. Dengan kata lain, Hasil belajar siswa yang telah mendapatkan pembelajaran kooperatif tipe TGT berbantuan Kartu Matematika Asyik lebih baik apabila dibandingkan dengan hasil belajardari siswa yang telah mendapatkan pembelajaran langsung(direct instruction).

\section{KESIMPULAN DAN SARAN}

\section{A. Kesimpulan}

Dari analisa data maupun pembahasan di atas, diperoleh kesimpulan yaitu: Ditinjau dari hasil belajarnya, Siswa yang telah mendapatkan pembelajaran kooperatif tipe TGT berbantuan Kartu Matematika Asyik lebih baik daripada siswa yang telah mendapatkan model pembelajaran langsung. Kedua metode dapat digunakan dalam mengasah atau melatih siswa dalam menyelesaikan soal matematika dengan baik.

\section{B. Saran}

Dalam melaksanakan pembelajaran kooperatif tipe TGT berbantuan Kartu Matematika Asyik, guru disarankan memperhatikan variasi soal (tingkat kesukaran) yang diberikan dalam setiap turnamen. Sedangkan dalam melaksanakan pembelajaran langsung, pemberian bimbingan (scaffolding) pada fase 3 perlu dirancang lebih sistematis serta guru perlu menggali ide dalam mendemonstrasikan materi dalam kegiatan lebih mudah dimengerti. 
Histogram: Jurnal Pendidikan Matematika, 3 (2), 2019 - 181

Indah Rahayu Panglipur, Ria Amalia

\section{DAFTAR PUSTAKA}

Coe, R., Aloisi, C., Higgins, S., \& Major, L. E. (2014). What makes great teaching? Review of the underpinning research. (October), 57. Retrieved from http://www.suttontrust.com/researcharchive/great-teaching/

Setyosari, P. (2012). Metode Penelitian Pendidikan dan Pengembangan. Jakarta: Kencana Prenada Media Grup.

Slavin. (2014). Kontektualisasi Direct Instruction Dalam Pembelajaran Sains. Lantanida Journal, 2(1), 95-106. https://doi.org/10.22373/lj.v2i1.667

Trianto. (2010). Mendesain Model Pembelajaran Inovatif - Progresif. Jakarta: Kencana Prenada Media Group. 